\title{
STUDY OF ISCHIOPUBIC INDEX IN PATIENTS COMING TO THE RADIOLOGY DEPARTMENT OF ALI ABAD TEACHING HOSPITAL
}

\author{
Dr. Jawid Azizi \\ Lecturer in Anatomy Department \\ Medical Faculty \\ Kabul University of Medical Sciences \\ Kabul, Afghanistan
}

\author{
Dr. Hidayatullah Danish \\ Lecturer in Anatomy Department \\ Medical Faculty \\ Kabul University of Medical Sciences \\ Kabul, Afghanistan
}

\begin{abstract}
The ischiopubic index was studied in adult pelvic X-ray films of subjects aged 18 to 60 years. A total of $120 \mathrm{X}$-ray films made of 60 males and 60 females were collected from Department of radiology Ali Abad Hospital. The ischiopubic index was calculated by dividing the pubic length by ischial length and by multiplying by 100.The mean ischiopubic index for males was 88, $5 \pm 5.1$ and that of the females was $106,8 \pm$ 4.3. Sex differences of these indices were statistically significant for both sexes. The mean length of the female's pubis was significantly longer than that for males, and similarly the mean length of ischium in males was significantly longer than that of the females. Using X-ray films, sex could be assigned using demarking points to $47 \%$ male and $50 \%$ females. Thus, the ischiopubic index may be of value in forensic and archaeological analyses and in solving medico legal cases.
\end{abstract}

Keywords: Radiographs, pubic length, ischial length, ischiopubic index, archaeology.

\section{BRIEF OUTLOOK}

The innominate bone has long been recognized as one of the best skeletal indicators of sex in an adult individual. Hip bone is consisting of three part, ilium, pubis and the ischium. These three parts together make the acetabulum. This bone makes the two important joints of the lower limbs, the sacro iliac and the hip joint. Meanwhile hip contributes to the pelvic inlet as well as the outlet. Methods have been developed which provide criteria for sex determination of adults using features of the innominate bone. Various studies have shown extensively that the hip bone is an ideal bone for sex determination because it reflects not only the general differences between the sexes but also the special adaptation of the female hip bone for childbearing. Hip bone of females was much longer than those of the males. This index was used efficiently where the pubic was separated and could determine sex in a high percentage of bones. The ischiopubic index is useful in sex differentiation it is obtained by dividing the length of pubis by the length of the ischium. This index is one of the determining factors of the size of the pelvic inlet and is significantly higher in females than in males. The results obtained will contribute to comparative data base for other studies.

\section{MATERIALS AND METHODS}

A total of 120 radiographs of the anterior-posterior view of the pelvis were collected comprising 60 males and 60 females. All the radiographs were collected from the department of radiology Ali Abad teaching Hospital Teaching Hospital Kabul. Only normal adult radiographs of subjects aged between 18 and 60 years were used. Materials included the X-ray illuminator, the radiographic films, a pencil, and transparent metric rule.

\section{BRIEF RESULTS}

The values of the data obtained from the X-ray measurements of the pubic and ischial lengths of the hip bone and their ischiopubic indices for the 120 radiographs are $81.0 \pm 5.0 \mathrm{~mm}, 91.7 \pm 8.1 \mathrm{~mm}$ and $88.5 \pm 5.1 \mathrm{~mm}$ for male and $92.7 \pm 7.3 \mathrm{~mm}, 87.3 \pm 7.2 \mathrm{~mm}$ and $106.8 \pm 4.3 \mathrm{~mm}$ for female respectively. The pubic length in females was observed to be higher than those of the males, while the ischial length of males was more than that of the females. Ischiopubic index in female is higher than the males. The mean ischiopubic index for male is $88.5 \pm 5.1 \mathrm{~mm}$ and that of for female is $106.8 \pm 4.3 \mathrm{~mm}$.

\section{BRIEF CONCLUSION}

In conclusion, this research has provided evidence that the ischiopubic index and the demarking points are reliable in sexing the hip bones of Afghans (using X-ray films). Thus 


\section{International Journal of Engineering Applied Sciences and Technology, 2019 \\ Vol. 4, Issue 4, ISSN No. 2455-2143, Pages 159-161 \\ Published Online August 2019 in IJEAST (http://www.ijeast.com)}

the ischiopubic index may be of value in forensic and archaeological analyses and in solving medico legal cases.

\section{INTRODUCTION}

The innominate bone has long been recognized as one of the best skeletal indicators of sex in an adult individual. Methods have been developed which provide criteria for sex determination of adults using features of the innominate bone $[1,2]$. Various studies have shown extensively that the hip bone is an ideal bone for sex determination because it reflects not only the general differences between the sexes but also the special adaptation of the female hip bone for child bearing [3-5].lschial bone of females was much longer than those of the males. This has been confirmed in adult black Malawians [5]. In the past many workers have evolved various metrical parameters and indices for sexing of the hip bone of which one of them is the ischiopubic index. This index was used efficiently where the pubic was separated and could determine sex in a high percentage of bones. The ischiopubic index is useful in sex differentiation [2]. It is obtained by dividing the length of pubis by the length of the ischium. This index is one of the determining factors of the size of the pelvic inlet and is significantly higher in females than in males [4]. . The results obtained will contribute to comparative data base for Nigerians [6] as well as compare those of other races.

Materials and Methods

A total of 120 radiographs of the anterior-posterior view of the pelvis were collected comprising 60 males and 60 females. All the radiographs were collected from the Department of radiology Ali Abad Teaching Hospital. Only normal adult radiographs of subjects aged between 18 and 60 years were used. Materials included the X-ray illuminator, the radiographic films, a pencil, and transparent metric rule.

\section{MEASUREMENT TECHNIQUE}

Measurement was carried out by choosing 3 points on the radiographs: points $\mathrm{A}, \mathrm{B}$ and $\mathrm{C}$. Points $\mathrm{A}$ were the acetabular point where the three pelvic bones meet. Points $\mathrm{B}$ and $\mathrm{C}$ were the ischial tuberosity and pubic tubercle respectively. A marker was used to mark these points for clear visualization. The distances between these points were then measured with the aid of verniercalliper. Distance AB gave the ischial length while AC gave the pubic length. Each distance was measured twice and average recorded as the actual distance to ensure accuracy. The distance AC was divided by the distance $\mathrm{AB}$, the resultant result was then multiplied by100. This gave the ischiopubic index. (IP = $\mathrm{AC} / \mathrm{AB} \mathrm{X} 100)$. Radiographs were placed on an X-ray view box for clear visualization.

Length of Ischium: This is a straight-line AC drawn from the center of the acetabulum rim to the lower point on inferior border of ischial tuberosity.

Length of Pubis: This is a straight-line AB drawn from the center of the acetabulum to the medial end of the pubis.

\section{RESULTS}

The values of the data obtained from the X-ray measurements of the pubic and ischial lengths of the hip bone and their ischiopubic indices for the 120 radiographs are shown in Tables 1 . The pubic length in females was observed to be higher than those of the males, while the ischial length of males was more than that of the females.

Table 1: Mean and Standard Deviation of measurement of Pubic, ischial length and their ischiopubic index

\begin{tabular}{|l|l|l|l|l|}
\hline $\begin{array}{l}\text { Subject } \\
\text { S }\end{array}$ & $\begin{array}{l}\text { Number } \\
\text { S }\end{array}$ & $\begin{array}{l}\text { Pubic } \\
\text { Length } \\
\pm \text { SD } \\
(\mathrm{mm})\end{array}$ & $\begin{array}{l}\text { Ischial } \\
\text { Length } \\
\pm \text { SD } \\
(\mathrm{mm})\end{array}$ & $\begin{array}{l}\text { Ischiopubic } \\
\pm \\
\text { index SD }\end{array}$ \\
\hline Male & 60 & $\begin{array}{l}81.0 \pm 5 . \\
0\end{array}$ & $\begin{array}{l}91.7 \pm 8 . \\
1\end{array}$ & $88.5 \pm 5.1$ \\
\hline Female & 60 & $\begin{array}{l}92.7 \pm 7 . \\
3\end{array}$ & $\begin{array}{l}87.3 \pm 7 . \\
2\end{array}$ & $106.8 \pm 4.3$ \\
\hline
\end{tabular}

SD-Standard Deviation

\section{DISCUSSION}

In the present study, the pubic and ischial length could not identify reasonable percentage of pelvis in both males and females though the mean values of these parameters were statistically significant when they were compared. The ischiopubic index was observed to be useful in sex differentiation. Igbigbi and Msamati measured the ischiopubic index in black Malawians and found that it was useful in sex determination using adult skeletons or X-ray film. In the present study, the mean pubic length of males was recorded as $81.0 \pm 5.0 \mathrm{~mm}$ while that of the females was $92.7 \pm 7.3 \mathrm{~mm}$. The ischial length for male was recorded as $91.7 \pm 8.1 \mathrm{~mm}$ and that of the females was $87.3 \pm 7.2 \mathrm{~mm}$. In a study in USA the mean ischiopubic index was 101.05 for males and 115.99 for females; when this was compared with the data of the present study, shows higher measurements. The sex differences in the pubic and ischial lengths were found to be statistically significant when male and female data were compared. Therefore the ischiopubic index is a useful parameter in sexing of hip bone.

\section{CONCLUSION}

This research has provided evidence that the ischiopubic index and the demarking points are reliable in sexing the hip bones of Nigerians (using X-ray films). Thus the ischiopubic index may be of value in forensic and archaeological analyses and in solving medico legal cases. 


\section{International Journal of Engineering Applied Sciences and Technology, 2019 Vol. 4, Issue 4, ISSN No. 2455-2143, Pages 159-161 \\ Published Online August 2019 in IJEAST (http://www.ijeast.com)}

\section{ACKNOWLEDGMENT}

This research was supported by Anatomy department of Kabul Medical University of Science. We thank our colleagues from the department who provided insight and expertise that greatly assisted the research.

We thank Ali Abad Teaching Hospital for assisting us in collection of the data and provided us inside to their archives.

\section{REFERENCES}

1. Washburn, S. L. (1949). Sex differences in the pubic bone of Bantu and Bushman. American Journal of Physical Anthropology, 7(3), 425-432.

2. Schulter-Ellis, F. P., Schmidt, D. J., Hayek, L. A., \& Craig, J. (1983). Determination of sex with a discriminant analysis of new pelvic bone measurements: Part I. Journal of Forensic Science, 28(1), 169-180.

3. Davivongs, V. (1963). The pelvic girdle of the Australian Aborigine; sex differences and sex determination. American Journal of Physical Anthropology, 21(4), 443-455.

4. Ekanem, T., Udongwu, A., \& Singh, S. (2009). Radiographic determination of sex differences in ischiopubic index of a Nigerian population. The Internet Journal of Biological Anthropology, 3(2), 1-6.

5. Igbigbi, P. S., \& Msamati, B. C. (2000). Ischio-pubic index in adult black Malawians. East African medical journal, 77(9), 514-516.

6. Ferembach, D. (1980). Recomendations for age and sex diagnosis of skeletons. Journal of human evolution, 9 , 517-549.

7. Boucher, B. J. (1955). Sex differences in the foetal sciatic notch. J Forensic Med, 2, 51-54.

8. Boucher, B. J. (1957). Sex differences in the foetal pelvis. American Journal of Physical Anthropology, 15(4), 581-600.

9. Rösing, F. W. (1983). Sexing immature human skeletons. Journal of Human Evolution, 12(2), 149-155.

10. Oladipo, G. S., Okoh, P. D., \& Leko, B. (2012). Radiologic studies of pubic length, ischial length and ischiopubic index of adult Kalabaris and Ikwerres of Nigeria. J Med Med Sci, 3, 99-102.

11. MacLaughlin, S. M., \& Bruce, M. F. (1986). Population variation in sexual dimorphism in the human innominate. Human Evolution, 1(3), 221-231.

12. Okoseimiema, S. C., \& Udoaka, A. I. (2013). Radiologic determination of ischiopubic index in southsouth Nigerian population. Asian Journal of Medical Sciences, 5(5), 96-100. 